\title{
Blood Vessel
}

National Cancer Institute

\section{Source}

National Cancer Institute. Blood Vessel. NCI Thesaurus. Code C12679.

A tubular structure through which the blood circulates in the body. Blood vessels

constitute a network composed of arteries, arterioles, capillaries, venules, and veins. 